\title{
Quantificação das Bactérias Sólido-Aderidas, Bactérias e Protozoários Líquido-Associados do Rúmen de Bovinos Jovens Alimentados com Amiréia
}

\author{
Jane Maria Bertocco Ezequiel ${ }^{1}$, Silvia Paula Livramento Melício², Juliana Borsari Dourado \\ Sancanari $^{3}$, Reginaldo Nassar Ferreira ${ }^{4}$, José Valmir Feitosa ${ }^{5}$
}

\begin{abstract}
RESUMO - Foram utilizados quatro bovinos mestiços, castrados, canulados no rúmen com o objetivo de quantificar as bactérias e protozoários líquido-associados, as bactérias sólido-aderidas e relacioná-las com o pH ruminal de bovinos recebendo amiréia dietética (30\% de uréia) no concentrado e silagem de milho. Realizaram-se três coletas de conteúdo ruminal, à 1h, às $2 \mathrm{~h} 30$ e 11 h30 após a alimentação. A massa microbiana foi quantificada e qualificada nas diferentes frações das bactérias sólido-aderidas (BSA), bactérias líquido-associadas (BLA) e protozoários líquido-associados (PLA) e seus teores de nitrogênio (N), de matéria seca (MS) e de matéria orgânica (MO), determinados. A população microbiana apresentou crescente contribuição das BSA no decorrer do tempo, o que não ocorreu com BLA e PLA. O teor de $\mathrm{MO} / \mathrm{MS}$ das BSA também aumentou o tempo $2 \mathrm{~h} 30$, permanecendo inalterado até $11 \mathrm{~h} 30$. Os teores de nitrogênio das BSA expressos na matéria orgânica diminuíram em tempos de coleta iguais ou superiores a $2 \mathrm{~h} 30$, embora os teores de $\mathrm{N}$ na matéria seca não apresentassem essa diferença. As relações entre bactéria:protozoário encontradas foram iguais a $1: 2,1$ à 1 h, 2,6: 1 às $2 \mathrm{~h} 30$ e 2,2: 1 às 11 h30 após a alimentação, quando foi observado predomínio de protozoários e bactérias, ambos associados ao líquido ruminal. As quantidades totais e as frações do "pool" microbiano ruminal não foram influenciadas pelo $\mathrm{pH}$, provavelmente, porque este se manteve sempre acima de 6,39.
\end{abstract}

Palavras-chave: matéria orgânica, matéria seca, microrganismos ruminais, nitrogênio

\section{Quantification of the Solid-Associated Bacteria and Liquid-Associated Bacteria and Protozoa from Rumen of Steers Fed with Starea}

\begin{abstract}
S - It were utilized four crossbreed, castrated, rumen cannuladed bovines, receiving dietary starea (containing $30 \%$ of urea) in the concentrate and corn silage, with the objective of quantify the liquid-associated bacteria and protozoa, solid-associated bacteria and related them with the ruminal $\mathrm{pH}$. Three samples from ruminal content were harvested at 1 a.m., 2 a.m. and $30 \mathrm{~min}$ and 11 a.m. and $30 \mathrm{~min}$ after feeding. The microbial mass was quantified and qualified in the different fractions of solid-associated bacteria (SAB), liquid-associated bacteria (LAB) and liquid-associated protozoa (LAP) and their nitrogen contents (N), dry matter (DM) and organic matter $(\mathrm{OM})$ were determined. The microbial population presented increasing contribution of SAB with the time, what did not occur with LAB and LAP. The level of OM in DM from the SAB increased as well, until 2 a.m. and 30 min when remains unaffected until 11 a.m. and $30 \mathrm{~min}$. The nitrogen levels of the SAB expressed in the organic matter decreased in equal or superior time of harvest at 2 a.m. and $30 \mathrm{~min}$, although the $\mathrm{N}$ level in the dry matter did not present this difference. The relations between bacteria:protozoa were equal to $1: 2.1$ at 1 hour, 2.6: 1 at $2 \mathrm{~h}$ and $30 \mathrm{~min}$ and 2.2: 1 at $11 \mathrm{~h}$ and $30 \mathrm{~min}$ after the feeding. It was still observed after feeding prevalence of protozoa and bacteria, both associated to the ruminal liquid. The total amounts and the ruminal microbial pool were not influenced by $\mathrm{pH}$, probably because it always maintained itself above 6.39 .
\end{abstract}

Key Words: dry matter, organic matter, nitrogen, ruminal microorganisms

\section{Introdução}

A ciência que estuda a nutrição animal tem à sua frente um grande desafio: desvendar a digestão dos ruminantes que, sem dúvida, ainda é muito complexa para ser completamente entendida. Estudos, pelo mundo inteiro, estão sendo realizados visando a descoberta de como os microrganismos transformam e sintetizam os alimentos durante o processo da digestão fermentativa (Martin et al., 1994; Cecava et al., 1990).

A quantidade de $\mathrm{N}$ exigida pelos microrganismos é função da quantidade de energia disponível no rúmen, porque os protozoários e bactérias precisam de $\mathrm{N}$ e energia, simultaneamente, para que ocorra uma proliferação desejável (Lucci, 1997).

\footnotetext{
1 Professora do Depto. de Zootecnia da FCAV-UNESP. Via de Acesso Paulo Donato Castellane, s/n Jaboticabal CEP 14870-000. E.mail: janembe@fcav.unesp.br

2 Aluna regular do curso de Pós-graduação em Produção Animal na FCAV-UNESP. E.mail: silmelicio@yahoo.com.br

3 Zootecnista, Dra. E.mail: juli@fcav.unesp.br

4 Professor do Instituto de Ciências Biológicas da Universidade Federal de Goiás. E.mail: nassar@icb2.ufg.br

${ }^{5}$ Aluno regular do curso de Pós-graduação em Produção Animal na FCAV-UNESP. E.mail: valfei@fcav.unesp.br
} 
Fontes de nitrogênio não-protéico (NNP) podem ser consideradas como um recurso viável à alimentação dos bovinos, pois os microrganismos ruminais são capazes de utilizá-las para sintetizar aminoácidos, que são absorvidos no intestino delgado dos ruminantes. A amiréia, produto da extrusão do milho com a uréia, fornece amido como fonte de energia para os microrganismos, e a uréia fica disponível no rúmen em forma de amônia após a transformação feita por eles.

Alguns trabalhos estão sendo feitos a fim de separar esses microrganismos para relacioná-los com os processos que ocorrem no rúmen. A literatura encontrada ainda é escassa, devido à dificuldade em isolar esses organismos tão pequenos. Desta forma, o presente trabalho teve por objetivo quantificar as bactérias e protozoários líquido-associados, as bactérias sólido-aderidas e relacioná-los com o $\mathrm{pH}$ ruminal de bovinos que receberam amiréia dietética contendo $30 \%$ de uréia e silagem de milho.

\section{Material e Métodos}

O experimento foi conduzido na Unidade Animal de Estudos Digestivos e Metabólicos na FCAVUNESP, Campus de Jaboticabal.

Foram utilizados quatro bovinos mestiços (zebuíno $\mathrm{x}$ taurino), castrados, com idade aproximada de 2 anos, peso médio de $375 \pm 68 \mathrm{~kg}$ e providos de cânulas permanentes no rúmen. No início do experimento, os animais foram submetidos ao controle de verminoses.

$\mathrm{O}$ alimento volumoso utilizado foi a silagem de milho. O concentrado usado era composto por amiréia (protemil R-30 / Nutrijet - Go), milho grão moído, Fosquima 80 (Agroquima - Go) e enxofre. A amiréia (protemil 30) era composta por 30\% de uréia e $70 \%$ de milho. Na Tabela 1, encontra-se a porcentagem dos ingredientes utilizados na formulação do concentrado.

Foi balanceada uma ração experimental a fim de atender aos requerimentos nutricionais dos bovinos, segundo as recomendações do AFRC (1993), de acordo com a capacidade máxima de ingestão do animal, obedecendo à relação volumoso : concentrado de 60:40\%.

Durante o período de coleta, foram realizadas amostragens dos alimentos para análise químicobromatológica, para determinação da matéria seca (MS), cinzas e proteína bruta (PB), segundo metodologias descritas por Silva (1990), e fibra em
Tabela 1 - Porcentagem dos ingredientes utilizados na formulação do concentrado

Table 1 - Percentage of the ingredients used in the formulation of the concentrate

Ingredientes

$\%$

Ingredients

Amiréia

11,04

Starea

Milho moído

86,86

Ground corn

Fosquima $80^{1}$

Fosquima 80

Enxofre

Sulfur

* Níveis garantidos: $120 \mathrm{~g}$ de $\mathrm{Ca} ; 80 \mathrm{~g}$ de $\mathrm{P} ; 10 \mathrm{~g}$; de $\mathrm{N} ; 6 \mathrm{~g}$ de $\mathrm{Mg}$; $152 \mathrm{~g}$ de Na; $15 \mathrm{~g}$ de S; $3800 \mathrm{mg}$ de Zn; $1900 \mathrm{mg}$ de Cu; $200 \mathrm{mg}$ de Co; $1000 \mathrm{mg}$ de $\mathrm{Mn} ; 150 \mathrm{mg}$ de I; $20 \mathrm{mg}$ de Se; $920 \mathrm{mg}$ de F; solubilidade do $\mathrm{P}=95 \%$

* Guarantee levels: $120 \mathrm{~g}$ of Ca; $80 \mathrm{~g}$ of P;10 $\mathrm{g}$ of $\mathrm{N} ; 6 \mathrm{~g}$ of Mg;152 $\mathrm{g}$ of Na; $15 \mathrm{~g}$ of S; $3800 \mathrm{mg}$ of $\mathrm{Zn} ; 1900 \mathrm{mg}$ of Cu; $200 \mathrm{mg}$ of Co; $1000 \mathrm{mg}$ of Mn; 150 $\mathrm{mg}$ of $\mathrm{l} ; 20 \mathrm{mg}$ of Se; $920 \mathrm{mg}$ of $F$; solubility of $P=95 \%$.

detergente ácido (FDA), segundo Van Soest \& Moore (1966).

Na Tabela 2, encontra-se a composição químicobromatológica da dieta fornecida aos animais, expressa na porcentagem de matéria seca.

A dieta experimental foi fornecida aos bovinos duas vezes ao dia, às 7 horas e às 19 horas, mantendose uma proporção de $20 \%$ de sobras. A água foi fornecida à vontade.

Os animais permaneceram durante toda a fase experimental em baias individuais, medindo 1,00 x $2,00 \times 1,55 \mathrm{~m}$ e distribuídas lado a lado com um espaçamento de $0,70 \mathrm{~m}$ uma da outra. Os animais permaneceram presos por cabrestos.

Os bovinos passaram por um período de adaptação à dieta e às condições de confinamento nas baias, por 21 dias, período em que receberam $1 / 3$ da quantidade total do concentrado na primeira semana, $2 / 3$ na segunda semana e, na terceira semana, foi oferecida a quantidade total do concentrado, seguida da primeira coleta.

Foram realizadas três coletas de conteúdo ruminal (3 kg) de cada animal, à 1h, 2 h30 e 11 h30 após a alimentação da manhã.

As coletas foram feitas com auxílio de bomba de sucção a vácuo, procurando amostrar todas as partes do rúmen. As amostras foram congeladas e, posteriormente, analisadas.

A partir dessas amostras de conteúdo ruminal, foi quantificada a massa microbiana (Figura 1), através da determinação, em diferentes frações, das bactérias 
Tabela 2 - Composição químico-bromatológica da dieta experimental

Table 2 - Chemical composition of the experimental diet

\begin{tabular}{lcccc}
\hline $\begin{array}{l}\text { Alimento } \\
\text { Roughage }\end{array}$ & $\begin{array}{c}\% \mathrm{MS}^{1} \\
\% \mathrm{DM}\end{array}$ & $\begin{array}{c}\% \mathrm{~PB}^{1} \\
\% C P\end{array}$ & $\begin{array}{c}\mathrm{FDA}^{1} \\
A D F\end{array}$ & $\begin{array}{c}\mathrm{FDN}^{1} \\
N D F\end{array}$ \\
\hline $\begin{array}{l}\text { Silagem de milho } \\
\text { Corn silage }\end{array}$ & 35,9 & 7,5 & 27,8 & 50,9 \\
$\begin{array}{l}\text { Concentrado } \\
\text { Concentrate }\end{array}$ & 88,6 & 17,0 & - & - \\
Vo:Co(\%) & $40: 60$ & & & \\
\hline
\end{tabular}

1 Lana-FCAVJ/UNESP; MS = matéria seca; PB = proteína bruta; FDA = fibra em detergente ácido; FDN = fibra em detergente neutro. Lana-FCAVJ/UNES; $D M=$ dry matter; $C P=$ crude protein; $A D F=$ acid detergent fiber; NDF = neutral detergent fiber.

sólido-aderidas (BSA), bactérias líquido-associadas (BLA) e protozoários líquido-associados (PLA), de acordo com a técnica proposta por Martin et al. (1994).

As amostras de conteúdo ruminal foram descongeladas por 12 horas em geladeira e, em seguida, foram filtradas em filtro de nylon com porosidade de $100 \mu \mathrm{m}$, para separar a fase líquida da fase sólida, de onde foram retiradas as frações microbianas.

\section{Identificação da fase líquida}

O líquido ruminal separado (1 litro) foi diluído com igual volume de solução tampão (solução de Coleman, 1978), pré-aquecida a $39^{\circ} \mathrm{C}$ com um ebulidor. Desses dois litros bem homogeneizados foi retirado 1 litro e incubado por 30 a 60 minutos em estufa a $39^{\circ} \mathrm{C}$. Nos últimos cinco minutos de incubação, foi adicionada glicose ( $1 \mathrm{~g}$ por litro), para separar os protozoários do restante do conteúdo ruminal e otimizar a floculação. Para que não ocorressem problemas na composição química da população microbiana, devido à adição de açúcar, a bactéria e o protozoário líquido-associados (BLA e PLA) foram isolados tão breve quanto possível, no máximo 30 minutos após a adição da glicose. $\mathrm{O}$ pélete de protozoário (PLA) foi recuperado por centrifugação do fluido clarificado, a $1000 \mathrm{x} \mathrm{g}$, por 10 minutos, à temperatura ambiente. Posteriormente, este pélete foi lavado com solução salina sobre um filtro de nylon, com porosidade de $20 \mu \mathrm{m}$ (11itro a $39^{\circ} \mathrm{C}$ ), para minimizar a contaminação por bactérias e resíduos de alimento.

A Figura 1 ilustra o esquema de separação das frações microbianas.

As bactérias líquido-associadas (BLA) foram obtidas pela centrifugação do fluido sobrenadante livre de protozoário a $15.000 \mathrm{x} \mathrm{g}$, por 20 minutos a $4^{\circ} \mathrm{C}$ (Figura 1).

\section{Identificação da fase sólida}

Segundo Merry \& McAllan (1993), citados por Martin et al. (1994), o sólido (200 g) foi lavado e agitado manualmente, por cinco minutos, em um frasco com solução salina, pré-aquecida a $39^{\circ} \mathrm{C}$ ( $1 \mathrm{~g}$ de material fresco/4 $\mathrm{mL}$ de solução), para remover a população não aderente associada à fase sólida. Após esse processo, foi realizada uma filtragem em filtro de náilon de $100 \mu \mathrm{m}$. O filtrado foi centrifugado a $1.000 \mathrm{xg}$, por 10 minutos, à temperatura ambiente, para recuperar o pélete de pequenas partículas de sólido que estavam associadas às grandes partículas que ficaram retidas no filtro. As partículas grandes e pequenas foram combinadas e suspensas em tampão ( $1 \mathrm{~g}$ de sólido/4 $\mathrm{mL}$ ) préresfriado a $4^{\circ} \mathrm{C}$ e, posteriormente, homogeneizadas três vezes por um minuto no Vórtex, em velocidade alta. O sólido foi colocado em saquinhos de náilon, e junto com o líquido, foram bombeados por cinco minutos em um "Stomacher" construído na própria Universidade. Esse aparelho é composto por um cilindro com tampa vedante, feito em PVC, com capacidade para $2 \mathrm{~L}$. Um êmbulo de acrílico perfurado percorre todo o seu interior, pressionado por uma alavanca de ferro que ficava acoplada em uma base de ferro que prende o aparelho. Este processo mecânico teve como objetivo separar a bactéria associada e algum fungo ou protozoário aderidos nas partículas, através da homogeneização por combinação de forças mecânicas, esmagando e agitando o material. O homogeneizado foi filtrado em um filtro de náilon com porosidade de $100 \mu \mathrm{m}$. O resíduo sobre o filtro foi lavado com a solução tampão ( $1 \mathrm{~g}$ de sólido/4 mL) e filtrado novamente. Os filtrados que continham a população aderente foram agrupados e centrifugados a $1.000 \mathrm{x} \mathrm{g}$, por 30 minutos, a $4^{\circ} \mathrm{C}$, para descartar o resíduo de alimento, e a fração sobrenadante foi centrifugada a $27.000 \mathrm{x}$ g durante 30 minutos a $4^{\circ} \mathrm{C}$ de temperatura. $\mathrm{O}$ sedimento resultante corresponde às $\mathrm{BSA}$.

Após liofilizar as amostras, os seus teores de N, MS e cinzas foram analisados, estimando-se os teores de MO.

Foram retirados $60 \mathrm{~mL}$ de líquido ruminal, nos horários das coletas, 1 h, 2 h30 e 11 h30 após a alimentação. Imediatamente após a retirada do líquido ruminal, esse foi coado em pano de queijo e, em seguida, foi realizada a leitura do $\mathrm{pH}$ com o auxílio de um potenciômetro Orion modelo $701 \mathrm{~A}$.

O delineamento foi em bloco casualizado (animais) em três tempos de amostragem. As variáveis 

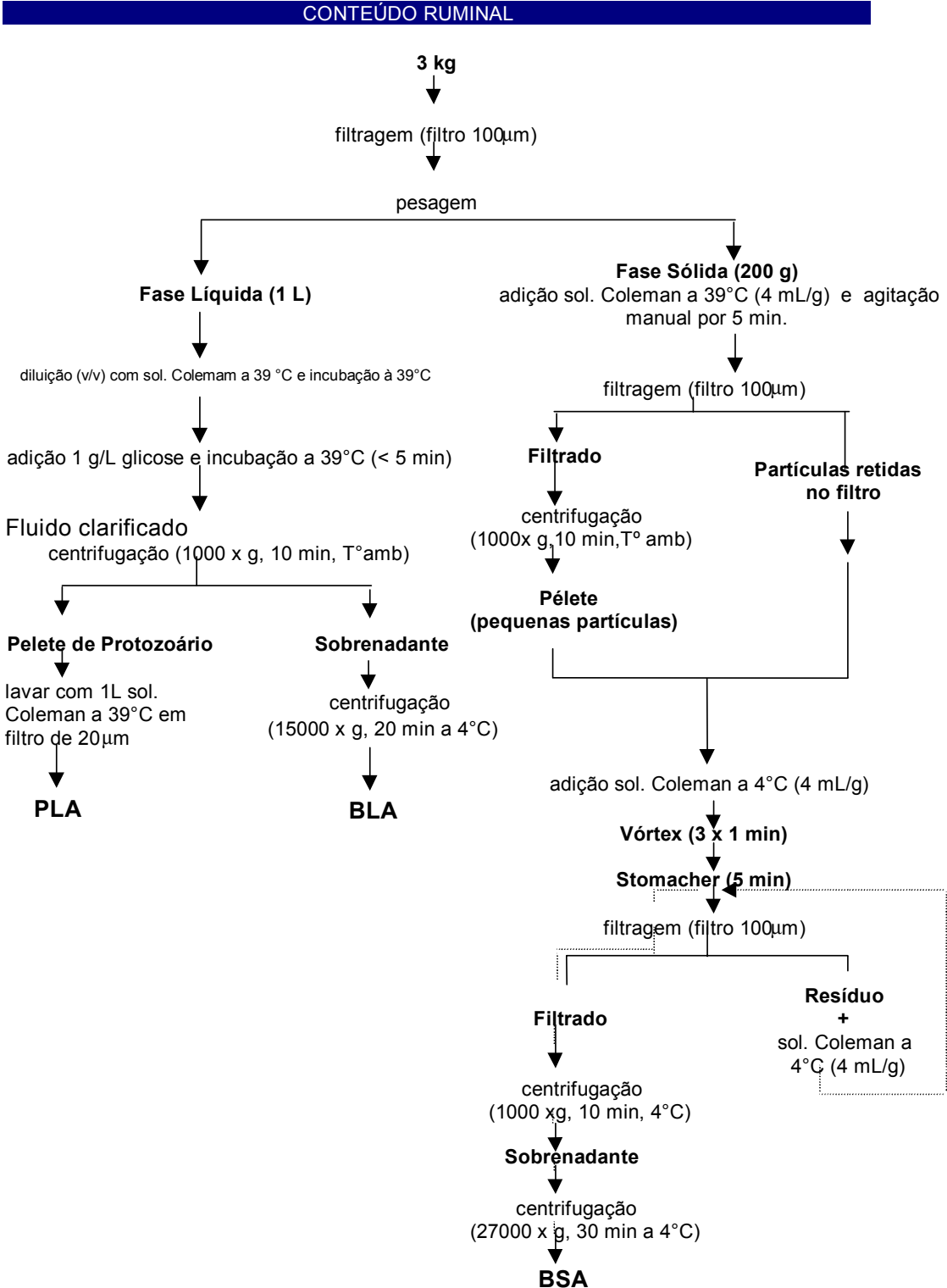

Figura 1 - Esquema de separação das frações microbianas. Figure 1 - Diagram of the isolation of the microorganisms fraction.

analisadas foram: quantidade de matéria seca por quilograma de conteúdo ruminal, porcentagem de matéria orgânica na matéria seca, nitrogênio na matéria seca, nitrogênio na matéria orgânica, total de microrganismos na fase sólida, total de microrganismos na fase líquida, porcentagem de bactérias totais e porcentagem de protozoários.

Odelineamento seguiu o seguinte modelomatemático:

$$
\mathrm{Y}_{\mathrm{ij}}=\mathrm{m}+\mathrm{b}_{\mathrm{i}}+\mathrm{t}_{\mathrm{j}}+\mathrm{e}_{\mathrm{ij}}
$$

em que:

$\mathrm{Y}_{\mathrm{ij}}=$ valor da variável dependente no tempo $(\mathrm{j}=1,2$ e 3$)$ no bloco (i=1,2,3 e 4);

$\mathrm{m}=$ média geral;

$\mathrm{b}_{\mathrm{i}}=$ efeito do bloco $\mathrm{i}$;

$\mathrm{t}_{\mathrm{j}}=$ efeito do tempo $\mathrm{j}$; e

$\mathrm{e}_{\mathrm{ij}}=$ erro aleatório associado à observação.

As médias dos tratamentos foram comparadas pelo teste de Tukey a $1 \%$. 


\section{Resultados e Discussão}

Na Tabela 3, encontram-se os dados referentes às médias da quantidade total de matéria seca (MS) por $\mathrm{kg}$ de conteúdo ruminal (CR) e as médias dos teores de matéria orgânica (MO) na MS, das diferentes frações de microrganismos nos diferentes tempos. Observou-se superioridade na quantidade de MS $\mathrm{BSA} / \mathrm{kg}$ de CR de 93,5 e 48,1\% às $11 \mathrm{~h} 30$, quando se compararam as coletas realizadas à $1 \mathrm{~h}$ e $2 \mathrm{~h} 30$ após a alimentação, respectivamente.

A média da quantidade de MS/ $\mathrm{kg}$ CR das BSA foi 16,0 e $69,2 \%$ superior, quando comparada com a dos demais microrganismos, PLA e BLA, respectivamente, dentro dos três tempos, sendo o valor médio encontrado igual a 4015,8 $\mathrm{mg} \mathrm{MS} / \mathrm{kg} \mathrm{CR}$. Isso pode evidenciar que, com o passar do tempo, as bactérias se aderem à fase sólida ou para se reproduzir ou para garantir o substrato.

$\mathrm{Na}$ literatura são descritas grandes variações na composição química dos microrganismos ruminais. Essas variações, provavelmente, são atribuídas às diferenças entre as técnicas utilizadas para isolar os microrganismos e/ou, medir sua composição, além de diferença entre espécies relacionadas ao perfil da dieta.

Em relação aos tempos de amostragem após a alimentação, os teores de matéria orgânica (Tabela 3) diferiram para a fração BSA, observando-se um aumento de $20,1 \%$ e $18,2 \%$ às $2 \mathrm{~h} 30 \mathrm{~min}$ e às $11 \mathrm{~h} 30 \mathrm{~min}$, respectivamente, quando comparados à 1 hora após o fornecimento do alimento, o que não foi observado para PLA. Verificou-se um valor mais elevado de MO às $2 \mathrm{~h} 30$ para BSA, quando comparado com as demais frações de microrganismos (BLA e PLA).

Considerando-se os teores médios de $\mathrm{MO}$, nos tempos de amostragem os valores mais elevados foram observados para BLA $(81,6 \%)$ e BSA $(81,2 \%)$ (Tabela 3). Martin et al. (1994), estudando o isolamento e características das frações de protozoários e bactérias do conteúdo ruminal de bovinos, relataram que, independentemente da dieta (no caso feno ou feno + cevada peletizada), o teor de MO de protozoários foi superior ao obtido para as frações bacterianas. Isto não foi verificado neste trabalho.

Os valores médios de MO, encontrados por Martin et al. (1994) para BLA, PLA e BSA, respectivamente, foram de $64,7 \% ; 84,9 \%$ e $77,2 \%$ (dieta de feno); e de $60,3 \% ; 94,2 \%$ e $78,3 \%$ (dieta de feno + cevada). Entretanto, Olubobokun et al. (1988) encontraram teores maiores de MO para a fração de bactérias sólido-aderidas, quando compararam dieta, tempo de amostragem e população microbiana, sendo de $87,3 \%$

Tabela 3 - Valores médios das quantidades e dos teores de matéria orgânica das frações de microrganismos, nos diferentes tempos de amostragem após alimentação

Table 3 - Average values of the amounts and content of organic matter of the microorganism fractions, in the different sample times after feeding

Fração microbiana

Microorganism fraction
Tempos de amostragem após alimentação

Sample times after feeding

\begin{tabular}{|c|c|c|c|c|}
\hline $1 \mathrm{~h}$ & $2 \mathrm{~h} 30$ & $11 \mathrm{~h} 30$ & $\begin{array}{c}\text { Média } \\
\text { Mean }\end{array}$ & $\mathrm{CV} \%$ \\
\hline $976,7^{a}$ & $941,8^{a}$ & $1788,2^{\mathrm{a}}$ & 1235,6 & 59,2 \\
\hline $3307,0^{\mathrm{a}}$ & $2487,0^{\mathrm{a}}$ & $4331,0^{\mathrm{a}}$ & 3375,0 & 55,8 \\
\hline $496,7^{\mathrm{c}}$ & $3945,1^{b}$ & $7605,6^{a}$ & 4015,8 & 21,2 \\
\hline & & $\begin{array}{l}\% \mathrm{MS} \\
\% D M\end{array}$ & & \\
\hline $79,0^{\mathrm{a}}$ & $80,6^{\mathrm{a}}$ & $85,3^{\mathrm{a}}$ & 81,6 & 3,6 \\
\hline $74,9^{\mathrm{a}}$ & $75,7^{\mathrm{a}}$ & $75,0^{\mathrm{a}}$ & 75,2 & 5,3 \\
\hline $70,1^{b}$ & $87,7^{\mathrm{a}}$ & $85,7^{\mathrm{a}}$ & 81,2 & 3,4 \\
\hline
\end{tabular}

MS = matéria seca, $\mathrm{CR}=$ conteúdo ruminal, $\mathrm{MO}=$ matéria orgânica.

Médias com letras diferentes nas linhas, indicam diferença significativa $(P<0,01)$.

$D M=$ dry matter; $R C=$ ruminal content; $O M=$ organic matter

Means with different letter, within a row, differ $(P<.01)$. 
$\mathrm{MO} / \mathrm{MS}$ resultados obtidos para $\mathrm{BSA}, 80,9 \% \mathrm{MO} / \mathrm{MS}$ para PLA e $80,1 \% \mathrm{MO} / \mathrm{MS}$ para a BLA.

Storm \& Orskov (1983), citados por Olubobokun et al. (1988), reportaram que o conteúdo de MO da fração de protozoários foi menor que a fração de bactéria obtida no rúmen. A concentração de $\mathrm{MO}$ das bactérias sólido-aderidas foi maior do que a das líquido-associadas. Essa observação está de acordo com os resultados de Merry \& McAllan (1983), quando reportaram que as BSA continham maior valor de MO do que as BLA, o que só ocorreu nesta pesquisa, quando a amostragem foi efetuada no horário $2 \mathrm{~h} 30$ após a alimentação. Esses resultados diferiram dos encontrados neste trabalho, em que foram observados valores de $81,6 \%$ para BLA e de $81,2 \%$ para BSA, porém assemelham-se com o relato de Cecava et al. (1990) que encontraram valores médios similares de $83 \%$ de MO para as frações de BLA e BSA.

Os resultados obtidos por Martin et al. (1994), diferem dos encontrados neste trabalho, provavelmente, devido às diferenças quanto ao manejo de alimentação e tipo de dieta. No presente estudo, os animais foram alimentados duas vezes ao dia, sendo o intervalo de arraçoamento de 12 horas e, no trabalho desenvolvido por Martin et al. (1994), a alimentação foi oferecida uma vez ao dia com intervalo de 24 horas.

Outro aspecto que deve ser levado em consideração são os tempos de amostragem que foram adaptados seguindo a diferença na freqüência de alimentação. Martin et al. (1994) coletaram as amostras 2, 5 e 23 horas após a alimentação e neste trabalho os tempos de amostragem foram à $1 \mathrm{~h}, 2 \mathrm{~h} 30$ e $11 \mathrm{~h} 30$ após a alimentação da manhã, correspondendo à mesma freqüência de coleta, se for considerado o intervalo de alimentação de 12 horas em vez de 24 horas.

Vale ressaltar também que, em seu trabalho, Martin et al. (1994) relataram a retirada de resíduos de alimentos (com auxílio de uma bomba a vácuo), após a incubação, realizada para o isolamento das frações microbianas líquido associadas. Esse resíduo, porém, não foi encontrado neste trabalho o que pode resultar em diferenças entre os resultados obtidos.

Burger et al. (1998) encontraram valores médios de MS de bactérias iguais a $89,86 \%$ e $92,52 \% \mathrm{MO} / \mathrm{MS}$, que são bem mais elevados do que os resultados já citados e encontrados neste trabalho.

Villela et al. (1997) verificaram que as bactérias apresentaram, em média, $88,9 \%$ de MS; $87,7 \%$ de
MO. Recentemente, Oliveira et al. (1999) encontraram valor médio de $87,58 \% \mathrm{MO} / \mathrm{MS}$ para a fração bacteriana e ressaltaram que este valor está de acordo com os valores encontrados em revisão feita por Clark et al. (1992), que descreveram variações na composição microbiana para MO. O valor médio de MO das frações bacterianas, do presente trabalho, foi $81,4 \%$.

Os valores médios de nitrogênio na MS (N/MS) e na MO (N/MO) encontram-se na Tabela 4. Os resultados de N/MS não apresentaram diferenças dentro dos tempos de obtenção das amostras. Comparando-se as médias das frações de microrganismos a maior média foi encontrada para a fração BLA $(5,4 \%)$. Verificou-se diminuição significativa de $22,5 \%$ às $2 \mathrm{~h} 30$ e de $28,2 \%$ às $11 \mathrm{~h} 30$ em relação ao primeiro tempo de amostragem, apenas para o N/MO das BSA, sendo o valor médio encontrado igual a $5,9 \%$ N/MO. É muito provável que esses resultados sejam conseqüência de menor $\% \mathrm{MO} / \mathrm{MS}$ obtida para BSA na colheita $1 \mathrm{~h}$ após a alimentação (Tabela 3 ).

A solução salina, nesta pesquisa, apresentou um precipitado. Foi, então, determinada a matéria seca desse precipitado na quantidade equivalente de solução salina utilizada para as lavagens, sendo descontada a quantidade de cinza obtida das amostras que apresentariam este resíduo. Dessa forma, foi descartada a hipótese de contaminação da solução salina.

Valadares Filho et al. (1990) encontraram valores médios de MO na MS das frações bacterianas de novilhos Holandeses e Nelores iguais a 82,45 e 85,14\%, respectivamente. Entretanto, houve grande variação nos teores de MS, atribuídos aos teores de cinzas, muito elevados nas amostras de bactérias. Provavelmente, isso ocorreu devido ao procedimento de lavagem das bactérias após serem centrifugadas com solução salina.

O conteúdo médio de N/MO da fração de protozoários PLA $(4,9 \%)$ foi mais baixo do que aquele das frações bacterianas $(6,7 \%$ de BLA e 5,9\% de BSA), confirmando os resultados obtidos por Martin et al. (1994) e Legay-Carmier \& Bauchat (1989), citados por eles.

Cecava et al. (1990) e Olubobokun \& Craig (1990) também encontraram teores superiores de N/MO de BLA em relação às BSA. Os valores obtidos por Cecava et al. (1990) foram iguais a 9,7\% para BLA e de $9,3 \%$ para BSA, valores bem mais elevados do que aqueles obtidos neste trabalho, o que pode ser atribuído a diferenças entre as dietas e metodologias 
Tabela 4 - Teores médios do N/MS e do N/MO das diferentes frações de microrganismos nos diferentes tempos de amostragem após alimentação

Table 4 - Mean contents of N/DM and N/OM in the different microorganism fractions in the different sample times after feeding

\begin{tabular}{|c|c|c|c|c|c|}
\hline \multirow[t]{2}{*}{$\begin{array}{l}\text { Fração microbiana } \\
\text { Microorganism fraction }\end{array}$} & \multicolumn{3}{|c|}{$\begin{array}{l}\text { Tempos de amostragem após alimentação } \\
\text { Sample times after feeding }\end{array}$} & \multirow[b]{2}{*}{$\begin{array}{l}\text { Média } \\
\text { Mean }\end{array}$} & \multirow[b]{2}{*}{$\mathrm{CV} \%$} \\
\hline & $1 \mathrm{~h}$ & $2 \mathrm{~h} 30$ & $11 \mathrm{~h} 30$ & & \\
\hline $\begin{array}{l}\text { N BLA/MS } \\
N L A B / D M\end{array}$ & $5,3^{\mathrm{a}}$ & $5,4^{\mathrm{a}}$ & $5,6^{\mathrm{a}}$ & 5,4 & 5,9 \\
\hline $\begin{array}{l}\text { N PLA/ MS } \\
N L A P / D M\end{array}$ & $3,6^{\mathrm{a}}$ & $3,7^{\mathrm{a}}$ & $3,7^{\mathrm{a}}$ & 3,7 & 17,2 \\
\hline $\begin{array}{l}\text { N BSA/MS } \\
N S A B / D M \mid\end{array}$ & $5,0^{\mathrm{a}}$ & $4,8^{\mathrm{a}}$ & $4,3^{\mathrm{a}}$ & 4,7 & 7,8 \\
\hline $\begin{array}{l}\text { N BLA/MO } \\
N L A B / O M\end{array}$ & $6,8^{\mathrm{a}}$ & $6,7^{\mathrm{a}}$ & $6,5^{\mathrm{a}}$ & 6,7 & 5,4 \\
\hline $\begin{array}{l}\text { N PLA/MO } \\
N L A P / O M\end{array}$ & $4,9^{\mathrm{a}}$ & $5,0^{\mathrm{a}}$ & $4,9^{\mathrm{a}}$ & 4,9 & 16,5 \\
\hline $\begin{array}{l}\text { N BSA/MO } \\
N S A B / O M\end{array}$ & $7,1^{\mathrm{a}}$ & $5,5^{\mathrm{b}}$ & $5,1^{\mathrm{b}}$ & 5,9 & 8,2 \\
\hline
\end{tabular}

$\mathrm{MS}$ = matéria seca, $\mathrm{CR}=$ conteúdo ruminal, $\mathrm{MO}=$ matéria orgânica, $\mathrm{N}=$ nitrogênio.

a,b,c - Médias com letras diferentes nas linhas diferem significativamente $(P<0,01)$.

$D M=$ dry matter; $R C=$ ruminal content; $O M=$ organica matter, $N=$ nitrogen .

Means with different letters within a row differ $(P<.01)$

de isolamento de microorganismos utilizadas.

Stokes et al. (1991) compararam a composição bacteriana de três diferentes dietas, compostas por 38 e $13,2 \%$ (dieta 1); 31 e 11,8\% (dieta 2 ); e 24 e $9 \%$ (dieta 3) de carboidratos não estruturais e proteína degradável dietéticos, respectivamente. Esses autores relataram que houve diferença na composição bacteriana, quando compararam as diferentes dietas. Os conteúdos bacterianos de $\mathrm{N}$ e cinzas foram similares entre as dietas 1 e 2 e maior para a dieta 3 . Conteúdos de $\mathrm{N}$ e cinzas de protozoários não foram afetados pelas dietas e os valores médios são um tanto menores que os reportados na literatura. $\mathrm{O}$ número de protozoários encontrados por estes autores foi mais elevado embora não diferente, com as dietas 1 e 2, comparado com a dieta 3. Os teores de $\mathrm{N}$ para as bactérias foram 8,$87 ; 8,87 ;$ e $8,01 \%$ e para os protozoários, de 6,$44 ; 5,55$; e $4,78 \%$ para as dietas 1, 2 e 3, respectivamente. Merry \& McAllan (1983) citaram valores de $8,0 \%$ de N para BLA e de $7,0 \%$ de $\mathrm{N}$ para BSA, valores que, assim como os apresentados por Stokes et al. (1991), foram superiores aos valores de $\mathrm{N}$ encontrados neste trabalho, sendo iguais a 5,1\% para BLA, 4,7\% para BSA e 3,7\% para PLA.

Valadares Filho et al. (1990) encontraram valores médios bacterianos de $8,8 \%$ N/MO e de 5,8\% N/MS. Bürguer et al (1998), estudando a fermentação ruminal e a eficiência microbiana, em bezerros alimentados com dietas contendo diferentes níveis de concentrado, encontraram valores médios elevados de N/MS de bactérias iguais a 8,25\%. Ladeira et al. (1999) acharam valores médios de nitrogênio total de bactérias igual a $6,9 \%$ que são semelhantes aos $7,7 \%$ de compostos nitrogenados encontrados por Villela et al. (1997). Em todos esses estudos, os resultados apresentados foram superiores aos encontrados neste trabalho, no qual os valores de N/MS e N/MO da fração de bactérias são iguais a 5,4\% e 6,7\% para BLA, fração microbiana que apresentou os valores mais elevados de $\mathrm{N}$.

Os valores de $\mathrm{pH}$ de acordo com o tempo de amostragem, foram 6,$39 ; 6,57 ; 6,56$, respectivamente, 1h; 2 h30 e 11 h30 após a alimentação. Não houve alteração no valor do $\mathrm{pH}$, quando se comparou os diferentes tempos de coleta. Os valores de $\mathrm{pH}$ permaneceram dentro dos níveis ideais para o desenvolvimento tanto das bactérias, que segundo Altmer $\&$ Dittmer (1966) devem estar entre 5,0 e 9,0, quanto para os protozoários, que devem estar na faixa entre 6,0 e 7,0 segundo Purser e Moir (1959), citados por Ruiz et al. (1992). O coeficiente de variação encontrado para os valores de $\mathrm{pH}$ foi igual a $1,8 \%$.

Foram calculadas as quantidades totais de microrganismos, resultantes do somatório das quantidades em mg de MS/kg CR das frações da microbiota ruminal, microrganismos totais das fases líquida e 
sólida e as porcentagens de bactérias e de protozoários. Esses resultados são apresentados na Tabela 5.

Foi observado aumento $(\mathrm{P}<0,01)$ na quantidade total de microrganismos às $11 \mathrm{~h} 30$, evidenciando a participação das BSA nesta diferença, por se apresentar em maior quantidade nesse horário.

Não ocorreram diferenças dentro de horários quando analisados os resultados de microrganismos associados à fase líquida (BLA + PLA), sendo achadas diferenças $(\mathrm{P}<0,01)$ para os microrganismos aderidos à fase sólida (BSA) nos três horários de coleta.

A relação bactéria:protozoário foi de $1: 2,1$ à 1hora, 2,6: 1 às $2 \mathrm{~h} 30$ e $2,2: 1$ às $11 \mathrm{~h} 30$, após a alimentação, invertendo-se com o decorrer do tempo pós-prandial. Esse fato torna a confirmar a participação das bactérias sólido-aderidas, com o passar do tempo, ocorrendo maior concentração desses microrganismos no substrato restante.

Clark et al. (1992) verificaram que a alteração da relação volumoso:concentrado na dieta pode influir no crescimento microbiano, em razão da variação na disponibilidade de energia.

Merry \& McAllan (1983) relataram, em seu trabalho, que bezerros recebendo dietas com proporções aproximadamente iguais de volumoso:concentrado apresentaram praticamente metade da população bacteriana ruminal associada com a fração sólida da digesta. Eles ainda citaram que ovelhas recebendo dietas somente com volumoso (Faichney, 1980), e bovinos recebendo dietas volumoso:concentrado (Wolstrup \& Jensen, 1978), acima de 90 e 77\%, respectivamente, da bactéria ruminal estava associada com a fração sólida da dieta.

Esses valores condizem com os resultados encontrados neste trabalho, pois a relação volumoso:concentrado foi de 60:40, e a relação entre as porcentagens representativas da quantidade de BLA e BSA (mg MS/kg de CR) foram de 24:76, respectivamente. A relação média de bactérias:protozoários encontrada foi de 57,4:42,59 diferindo do relato feito por Moon \& Choi (1994) que reportaram a relação protozoário:bactéria sendo 35:65, quando utilizaram uma dieta contendo $50 \%$ de concentrado e $50 \%$ de palha de arroz.

Ruiz et al. (1992) citaram que a diferença de velocidade de passagem dos diferentes alimentos pelo rúmen favorece a ação dos microrganismos sobre eles. Os alimentos que estão no saco ventral (fase líquida) são rapidamente fermentados e os microrga-

Tabela 5 - Valores das quantidades totais de microrganismos, microrganismos totais das fases líquida e sólida e as porcentagens de bactérias e de protozoários

Table 5 - Values of the total content of microrganismos, total microrganisms of the liquid and solid phases and the percentages of bacterias and of protozoa

Fração microbiana

Microorganism fraction
Tempos de amostragem após alimentação

Sample times after feeding

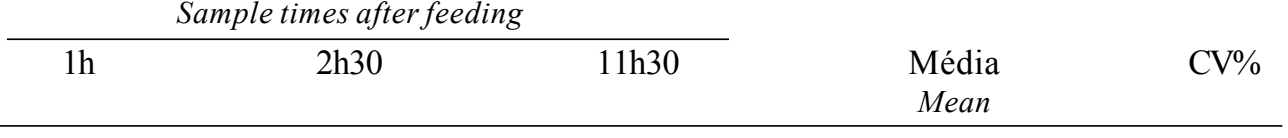

$\mathrm{mg} \mathrm{MS} / \mathrm{kg} \mathrm{CR}$

$m g D M / k g R C$

Microrg. fase líquida

Liquid microorg. phase

Microrg. fase sólida

Solid microorg. phase

Quantidade total de

$4284,0^{\mathrm{a}}$

$3429,0^{\mathrm{a}}$

$6120,0^{\mathrm{a}}$

4611,0

48,1

$496,7^{\mathrm{c}}$

$3945,1^{b}$

$7605,6^{\mathrm{a}}$

4015,8

21,2

$4781,0^{\mathrm{b}}$

$7374,0^{\mathrm{b}}$

$13725,0^{\mathrm{a}}$

8626,7

29,7

Total quantity of mricroorgnisms

Bactéria

Bacterial

Protozoário

$31,9^{b}$

$68,1^{\mathrm{a}}$

Protozoal

$\mathrm{Ms}=$ matéria seca, $\mathrm{CR}$ = conteúdo ruminal, $\mathrm{MO}=$ matéria orgânica, $\mathrm{N}=$ nitrogênio.

a,b,c - Médias com letras diferentes, nas linhas diferem significativamente $(P<0,01)$.

$D M=$ dry matter; $R C=$ ruminal content; $O M=$ organica matter, $N=$ nitrogen.

$M$ eans with different letters within a row, differ $(P<.01)$.

R. Bras. Zootec., v.31, n.2, p.707-715, 2002
$\%$ de microrganismos

$\%$ of microorganisms

$71,9^{\mathrm{a}} \quad 68,5^{\mathrm{a}}$

57,4

21,4

42,6

28,9 
nismos podem prontamente atingir o estômago verdadeiro. Já as grandes partículas de vegetais (fase sólida) permanecem por mais tempo no saco dorsal, onde os microrganismos têm crescimento lento, e pelo fato de estarem associados à partículas maiores, permanecem no rúmen por maior tempo. Essa pode ser uma explicação para a maior quantidade encontrada de BSA com o decorrer do tempo.

Todos os resultados encontrados neste trabalho não diferiram significativamente quando comparados entre animais utilizados.

\section{Conclusões}

Após a alimentação, predominam protozoários e bactérias associados à fase líquida, sendo predominante a população de protozoários, porém declinando rapidamente pós-prandialmente. A maior parte da população microbiana é representada pelas bactérias sólido-aderidas. As quantidades totais e as frações do "pool" microbiano ruminal não foram influenciadas pelo $\mathrm{pH}$, embora este se mantivesse sempre acima de 6,39.

Mais estudos são necessários para testar diferentes metodologias de isolamento microbiano.

\section{Literatura Citada}

AGRICULTURAL AND FOOD RESEARCH COUNCIL $A F R C$. Energy and protein requeriments of ruminants. Wallingford: CAB, 1993. 159p.

BURGER, P.J.; PEREIRA, J.C.; VALADARES FILHO, S.C. et al. Fermentação ruminal e eficiência microbiana em bezerros alimentados com dietas contendo diferentes níveis de concentrado. In: Reunião Anual da Sociedade Brasileira de Zootecnia. 35., 1998, Botucatu. Anais... Botucatu: Sociedade Brasileira de Zootecnia, 1998. p.602-604.

CECAVA, M.J.; MERCHEN, N.R.; GAY, L.C. et al. Composition of ruminal bacteria harvested from steers as influenced by dietary energy level, feeding frequency, and isolation techniques. Journal of Dairy Science, v.73, n.9, p.2480-2888, 1990.

CLARK, J.K.; KLUSMEYER, T.H.; CAMERON, M.R. Microbial protein synthesis and flows of nitrogen fractions to duodenum of dairy cows. Journal of Dairy Science, v.73, n.8, p.2304-2323, 1992.

COLEMAN, G.S. Rumen entodiniomorph protozoa. In: TAYLOR, A.E.R.; BAKER, J.R. (Eds.) The roles of protozoa and fungi in ruminant digestion. Armidale: Penambul Books, 1978. p.13.

LADEIRA, M.M.; VALADARES FILHO, S.C.; LEÃO, M.I. et al. Eficiência microbiana, concentração de amônia e pH ruminal e perdas nitrogenadas endógenas, em novilhos Nelore. Revista Brasileira de Zootecnia, v.28, n.2, p.404-411, 1999.

LUCCI, C.S. Nutrição e manejo de bovinos leiteiros. São Paulo: Manole, 1997.

R. Bras. Zootec., v.31, n.2, p.707-715, 2002
MARTIN, C.; WILLIAMS, A.G.; MICHALET-DOREAU, B. Isolation and Characteristics of the Protozoal and bacterial fractions from bovine ruminal contents. Journal of Animal Science, v.72, n.11, p.2962-2968, 1994.

MERRY, R.J.; MCALLAN, A.B. A comparison of the chemical composition of mixed bacteria harvested from the liquid and solid fractions of rumen digesta. British Journal of Nutrition, v.50, p.701-709, 1983.

MOON, Y.H.; CHOI, C.K. Chemical composition and pepsin digestibility of ruminal total microorganism, bacteria and protozoa. Korean Journal of Dairy Science, v.16, n.4, p.335-342, 1994.

OLIVEIRA, R.L.; PEREIRA, J.C.; SILVA, P.R.C. et al. Características ruminais e eficiência microbiana em novilhos alimentados com cama de frango e suplemento à base de microbiota ruminal liofilizada. Revista Brasileira de Zootecnia, v.28, n.5, p.1118-1124, 1999.

OLUBOBOKUN, J.A.; CRAIG, W.M.Quantity of characteristics of microorganisms associated with ruminal fluid or particles. Journal of Animal Science, v.68, n.10, p.3360-3370, 1990.

OLUBOBOKUN, J.A.; GRAIG, W.M.; NIPPER, W.A. Characteristics of protozoal and bacterial fractions from microorganisms associated whit ruminal fluid or particles. Journal of Animal Science, v.66, n.10, p.2701, 1988.

RUIZ, R. L. Microbiologia zootécnica. São Paulo: Roca, 1992. p.123-167.

SILVA, D.J. Análise de alimentos: métodos químicos e biológicos. Viçosa, MG: Universidade Federal de Viçosa, 1990. 166p.

STOKES, S.R.; MILLER, T.K.; BLAUWEIKEL, R. Ruminal digestion and microbial utilization of diets varying in type of carbohydrate and protein. Journal of Dairy Science, v.74, n.3, p.871, 1991.

VALADARES FILHO, S.C.; COELHO DA SILVA, J.F.; SANT'ANNA, R. et al. Composição de bactérias ruminais e absorção de aminoácidos microbianos no intestino delgado de novilhos Holandeses, Nelores e Búfalos mestiços. Revista da Sociedade Brasileira de Zootecnia, v. 19, n.5, p.431-440, 1990.

Van SOEST, P.J.; MOORE, L.A. New chemical methods for analysis of forrage for the purpose of predictting the nutritive value. In: CONGRESSO NACIONAL DE PASTAGENS, 9., 1966, São Paulo. Anais... São Paulo: 1996. p.783-789.

VILLELA, S.D.; VALADARES FILHO, S.C.; COELHO DA SILVA, J.F. et al. Caroço de algodão para vacas leiteiras. 3. Efeito na eficiência microbiana, concentração de amônia e pH ruminais. Revista Brasileira de Zootecnia, v.26, n.1, p.195-200, 1997.
Recebido em: 11/06/01

Aceito em: 06/11/01 